\title{
Aspirin Prophylaxis for Migraine with Aura: An Observational Case Series
}

\author{
Wendy E. Turk ${ }^{\mathrm{a}} \quad$ Anouk Uiterwijk $^{\mathrm{a}} \quad$ Raphaël Pasmans $^{\mathrm{a}} \quad$ Vera Meys $^{\mathrm{a}}$ Cenk Ayata ${ }^{\mathrm{b}}$ \\ Peter J. Koehler ${ }^{\mathrm{a}}$ \\ ${ }^{a}$ Department of Neurology, Zuyderland MC Heerlen, Heerlen, The Netherlands; ${ }^{b}$ Stroke Service and Neuroscience \\ Intensive Care Unit, Neurovascular Research Unit, Massachusetts General Hospital, Harvard Medical School, \\ Charlestown, MA, USA
}

Dear Sir,

Migraine with aura is an independent risk factor for ischemic stroke [1]. Data indirectly suggest that migraine aura may indeed be triggered by transient ischemic events [2-6], and that aspirin may play a role, particularly in case of new onset or frequent migraine auras. Aspirin has been suggested in migraine prophylaxis [7-9]; although none of the studies found a statistically significant effect [10-14], these studies did not make a clear distinction between migraine with or without aura either. Ongoing debate prompted us to conduct a retrospective case study to observe the effect of aspirin prophylaxis on aura and headache in patients suffering from migraine with aura.

Starting in 2010, all migraine with aura patients older than 30 years of age with frequent auras ( $>2$ per month) were started on prophylactic aspirin (80 $\mathrm{mg}$ daily) at our outpatient clinic, and data were collected retrospectively from patient files. In case of missing data, patients were contacted by telephone. The following data were collected: age, gender, aura frequency and type of aura, presence of and type of headache, and length of follow-up. Vascular risk factors such as history of smoking, hypertension, diabetes mellitus, cerebrovascular accident, myocardial infarction, and use of oral contraceptives were also collected. Statistical analysis was carried out using Student paired $t$ test.

Forty-nine patients, fulfilling the ICHD-II criteria for migraine with aura, were treated with aspirin prophylaxis 80 mg once daily. An MRI-scan of the brain was done in 25/49 patients, which did not reveal any relevant abnormalities. Two patients were lost to follow-up, since they discontinued aspirin within 2 weeks due to side effects. Five other patients were lost to follow-up due to the inability to contact them. No side effects were reported in the remaining patients. Patient characteristics at inclusion are presented in Table $1(n=$ 42). The majority of patients were women, and the mean age was 57 years. The mean aura frequency was $10.2 /$ month. The auras were visual, with additional sensory or hemiplegic phenomena in five patients. The 2 patients with hemiplegic migraine did not have a family history of hemiplegic migraine. Both were negative for FHM1, FHM2 was not tested. A total of 12 patients did not suffer from headache following auras, whereas 22 had migraine headache, and 10 reported another type of headache. The mean follow-up of the 42 included patients was 10.2 months. The frequency of migraine aura decreased in 39/42 cases
(93\%), with complete disappearance of auras in 20 patients (48\%; Table 2). Many of these 20 patients reported disappearance of the auras soon after starting aspirin treatment. Three patients did not experience any benefit and endured the same aura frequency. These were women aged 45, 51, and 56 years with highly frequent auras (16, 20 , and 31 per month). At follow-up, the mean aura frequency had decreased from 10.2 to 2.3 times per month $(p<0.001)$. Although we did not check the number of headache days at follow-up, most of the 30 patients, who had headache following their aura, experienced a reduction.

In this retrospective observational case study, we found a remarkable suppression of aura frequency by aspirin prophylaxis in migraine with aura patients. We did not find any indication of secondary migraine auras. Brain-MR scans were done in 25/49 patients and auras were distinct in all cases. The majority of patients had suffered from migraine in the past. One of us (P.J.K.) participated in a study of late-onset migraine ( $>40$ year), in which no relevant abnormalities were found despite intensive work-up (including scans, laboratory tests, and carotid studies) [15].

Although we do not know the precise mechanisms underlying this effect, it may involve the prevention of mild and tran-
KARGER

(C) 2017 S. Karger AG, Basel

E-Mail karger@karger.com

www.karger.com/ene
Peter J. Koehler, $\mathrm{MD}, \mathrm{PhD}$ Department of Neurology Zuyderland Medical Centre H. Dunantstr. 5 NL-6419PC Heerlen (The Netherlands) E-Mail pkoehler@neurohistory.nl 
Table 1. Patient characteristics

Table 2. Frequency of auras per month before (left column) and after taking aspirin $(n=42)$
Number of patients

Gender

Age, years, mean (range)

Length of follow-up, mean (range)

Type of aura

Visual

Sensory

Hemiplegic

Mean aura frequency

Headache absent

Headache present

Migraine headache

Other types of headache

Presence of any vascular risk factor (smoking,

DM, HT, CVA, MI, use of oral contraceptive) 29 patients

DM, diabetes mellitus; HT, hypertension; CVA, cerebrovascular accident; MI, myocardiac infarction.
42

32 women, 10 men

57 (34-70)

10.2 months (20 days to 64 months)

42 patients

3 patients

2 patients

10.2 times per month

12 patients

30 patients

22 patients

10 patients

\begin{tabular}{rr|rr}
\hline 6 & 2 & 4 & 1 \\
31 & 3 & 31 & 31 \\
31 & 0 & 20 & 20 \\
20 & 2 & 4 & 0 \\
15 & 0.25 & 8 & 1 \\
4 & 0 & 8 & 0.33 \\
2 & 0 & 4 & 0.5 \\
60 & 0 & 12 & 0 \\
4 & 0 & 24 & 4 \\
16 & 0.33 & 16 & 0 \\
4 & 0 & 15 & 2 \\
4 & 0 & 25 & 1 \\
16 & 16 & 2 & 1 \\
4 & 0 & 8 & 2 \\
12 & 4 & 4 & 0 \\
4 & 0 & 12 & 0 \\
4 & 0.25 & 4 & 0 \\
8 & 0 & 5 & 0 \\
20 & 2 & 8 & 0 \\
3 & 0 & 10 & 1 \\
4 & 0 & & \\
\hline
\end{tabular}

sient hypoxic-ischemic events (e.g., microembolism) as a trigger for cortical spreading depression, the electrophysiological basis of migraine aura, or reduction of platelet serotonin release, and plasma serotonin concentrations. We believe that in previous studies, the aspirin effect was not observed because migraine with or without aura were not distinguished. Moreover, we included only patients over 30 years of age, who had highly frequent auras. The effect of regression to the mean cannot be ruled out, although we had a reasonable median follow-up of 10.2 months and it is unlikely that the results are entirely explained by this phenomenon. Moreover, many of the 20 patients with complete disappearance of the auras reported that the auras disappeared soon after starting aspirin treatment, suggesting a temporal association. Nevertheless, although this observational series resulted in a remarkable reduction in aura frequency, a prospective randomized con- trolled trial for migraine aura is necessary to confirm the effect and modify the practice. We suggest that, until then, aspirin may be tried in patients in whom other prophylactic drugs are contraindicated or not tolerated.

\section{Disclosure Statement}

The authors have no conflicts of interest to disclose. There was no financial support for this work. 


\section{References}

1 Schürks M, Rist PM, Bigal ME, Buring JE, Lipton RB, Kurth T: Migraine and cardiovascular disease: systematic review and meta-analysis. BMJ 2009;339:b3914.

2 Nozari A, Dilekoz E, Sukhotinsky I, Stein T, Eikermann-Haerter K, Liu C, Wang Y, Frosch MP, Waeber C, Ayata C, Moskowitz MA: Microemboli may link spreading depression, migraine aura, and patent foramen ovale. Ann Neurol 2010;67:221-229.

3 Mawet J, Kurth T, Ayata C: Migraine and stroke: in search of shared mechanisms. Cephalalgia 2015;35:165-181.

4 Dalkara T, Nozari A, Moskowitz MA: Migraine aura pathophysiology: the role of blood vessels and microembolisation. Lancet Neurol 2010;9:309-317.

5 Bashir A, Lipton RB, Ashina S, Ashina M: Migraine and structural changes in the brain: a systematic review and meta-analysis. Neurology 2013;81:1260-1268.

6 de Ceuster L, van Diepen T, Koehler PJ: Migraine with aura triggered by cardiac myxoma: case report and literature review. Cephalalgia 2010;30:1396-1399.

7 Evers S: [Alternatives to beta blockers in preventive migraine treatment]. Nervenarzt 2008;79:1135-1136, 1138-1140, 1142-1143.

8 Massiou H, Bousser MG: [Prophylactic drug treatment of migraine]. Rev Neurol (Paris) 2005; 161:681-684.

9 Nelson-Piercy C, De Swiet M: Diagnosis and management of migraine. Low dose aspirin may be used for prophylaxis. BMJ 1996;313: 691-692.

10 Grotemeyer KH, Scharafinski HW, Schlake HP, Husstedt IW: Acetylsalicylic acid vs. metoprolol in migraine prophylaxis - a dou- ble-blind cross-over study. Headache 1990; 30:639-641.

11 O'Neill BP, Mann JD: Aspirin prophylaxis in migraine. Lancet 1978;2:1179-1181

12 Buring JE, Peto R, Hennekens CH: Low-dose aspirin for migraine prophylaxis. JAMA 1990; 264:1711-1713.

13 Peto R, Gray R, Collins R, Wheatley K, Hennekens C, Jamrozik K, Warlow C, Hafner B, Thompson E, Norton S, et al: Randomised trial of prophylactic daily aspirin in British male doctors. Br Med J (Clin Res Ed) 1988; 296:313-316.

14 Benseñor IM, Cook NR, Lee IM, Chown MJ, Hennekens $\mathrm{CH}$, Buring JE: Low-dose aspirin for migraine prophylaxis in women. Cephalalgia 2001;21:175-183.

15 Cull RE: Investigation of late-onset migraine. Scott Med J 1995;40:50-52. 